\title{
PROTECTIVE COLORATION IN ANIMALS
}

\author{
Leena Lakhani \\ Govt. Girls P.G. College, Ujjain (M.P.) India \\ leenalakhani56@gmail.com
}

\section{INTRODUCTION}

Animals have range of defensive markings which helps to the risk of predator detection (camouflage), warn predators of the prey's unpalatability (aposematism) or fool a predator into mimicry, masquerade. Animals also use colors in advertising, signalling services such as cleaning to animals of other species, to signal sexual status to other members of the same species. Some animals use color to divert attacks by startle (dalmatic behaviour), surprising a predator e.g. with eyespots or other flashes of color or possibly by motion dazzle, confusing a predator attack by moving a bold pattern like zebra stripes. Some animals are colored for physical protection, such as having pigments in the skin to protect against sunburn; some animals can lighten or darken their skin for temperature regulation.

This adaptive mechanism is known as protective coloration. After several years of evolution, most animals now achieved the color pattern most suited for their natural habitat and role in the food chains. Animals in the world rely on their coloration for either protection from predators, concealment from prey or sexual selection. In general the purpose of protective coloration is to decrease an organism's visibility or to alter its appearance to other organisms. Sometimes several forms of protective coloration are superimposed on one animal.

\section{TYPES OF PROTECTIVE COLORATION PREVENTIVE DETECTION AND RECOGNITION \\ CRYPSIS AND DISRUPTION}

Cryptic coloration helps to disguise an animal so that it is less visible to predators or prey. Most common cryptic coloration is background matching, which may take various forms. Many helplessanimals have developed colors and markings that match their surroundings in order to hide from predators. There are some examples of camouflage- Fish eggs and zooplanktons are transparent and nearly visible as they drift in the upper layers of oceans and fresh water lakes. The decorator crab, cements bits of algae, seaweed and other ocean debris onto its shell, so that it resembles the ocean floor. Grasshoppers and other insects that live among green plants are often green and insects that live in the soil are often earth colored. The pepper moth has colored patches that camouflage against the tree on which it lives. The oriental leaf butterfly, which lives on leaf, littered woodland floors, it is completely camouflaged that it markings include leaf veins and a stem.

American bird potto and Tawny Frogmouth are one of the camouflage experts in the animal kingdom. Its feathers show dried bark and tree branches pattern, exposed only when opens its beak or flutters a wing and flies out after dark to catch insects. Nightjars are colored brown and black, that hides them well on their terrestrial nests. Owls are nocturnal predators and spend most of day hiding in tree burrows, their dull plumage blends into the tree, and they are indeed very hard to spot during day time. 


\section{INTERNATIONAL JOURNAL of RESEARCH -GRANTHAALAYAH

The green vine snake effortlessly blends into foliage and is virtually undetectable unless it descends from its perch or moves suddenly. Sand grouse are terrestrial birds, are colored in shade of brown that hide them excellently in their sandy habitat.

Sometimes predator are camouflaged certain predatory fishes blend with harmless schooling fish and then prey on members of the school. Some species of fishes camouflaged against the ocean floor as they lie motionless, waiting for prey to swim by.

\section{DISRUPTIVE COLORATION}

Another form of Cryptic coloration is called disruptive coloration, is the presence of stripes or spots, which divide the body into separate areas and renders the animal unrecognizable against the background. Disruptive coloration which is often combined with cryptic coloration, characterizes many animals, including the cheetah, tiger, leopard giraffe, Zebra, Asiatic chipmunk, some fishes, various amphibians, some snakes, some birds, grasshoppers, many butterflies etc. Tigers hunt primarily in forested areas, in terrain covered with long grasses. Since they usually hunt at dawn or dusk, their conspicuous stripes allow them to advance unseen through the long grass. Both leopards and jaguar hunt in heavily forested areas.

Alluring coloration some animals are colored, so that a predator's attention is drawn to a non-vital part of the animal's body. The lizard (blue tailed skink) has a blue tail, when predators are attracted to the tail, if they attack the tail, the skink shed it with no harm to itself and darts away unharmed.

\section{SEASONAL CHANGES}

This phenomenon is commonly observed in tundra, several animals sport different coats in the summer and in winter. The winter coats of these animals are white, helping them blend with the omnipresent mass of snow and ice. In the winter, the white coats help these animals either escaping from predators or ambush prey. As summer rolls around, the white coats make way for brown and black coats, while help the animal hide in the summer landscape. Hares change their color with the season, in the winter their fur becomes white, and when the snow disappears, their fur turn brown. Thus they remain camouflaged throughout the year. Other examples are cuttle fish, octopus and some fishes. The skin of these animals, having various pigments, that expands or contract, upon receiving impulses from the central nervous system. The impulses originate from eyes.

\section{CONSPICUOUSNESS AND CONCEALMENT WARNING COLORATION (APOSEMATISM)}

An animal with aposematic coloration stands out against its background. The combination of bright coloring with various protective adaptations has acquired the name "warning coloration". This type of coloration is found in those animals that have natural defences they use to deter or fend off predators.

These defensive adaptations are of many types. An animal may cause a disagreeable smell (such as skunk's odour) or it may actually cause pain (as from bee's sting) or even death (as from snake's venom). The monarch butterfly bears a conspicuous pattern of bright orange and black has such a disagreeable taste, therefore a bird will often regurgitate after eating it. Predatory animals are likely to pass them up as potential prey in favour of a drabber animal. Common warning colors are red, black, and yellow. 


\section{INTERNATIONAL JOURNAL of RESEARCH -GRANTHAALAYAH

Some organisms can change their color from drab to bright when threatened. The octopus turns white when agitated and red when it is suddenly frightened. Chameleons display a brightly colored throat sac or dewlap, warning signal to invaders. When a male chameleon enters another's territory, the dewlap display of the territory, owner, serves as a warning to keepit out.

Some examples of warning coloration are: Caterpillars employ two types of protective coloring: camouflage and warning. Many caterpillars are colored just like the plant they grow upon, making them harder to spot for birds and other predators. A Lion's golden coat conceals it in the golden brown terrain of the Africa savannahs. Lions try to get as close as they can to their prey, so that their lack of speed doesn't matter that much in the hunt, their camouflage is crucial to that end. Golden poison dart frogs are most poisonous animals in the world, their attractive coloration actually serves as a warning to potential predator. Interestingly, the frogs are not venomous, i.e. the poison is not produced by the frog themselves. It is thought to be occurred through their diet of insects, that contains poisonous substance.

A large number of snakes are unbelievable masters of concealment and camouflage. The copper head, one of the deadliest and most notorious snakes of the North America, has a stunning pattern of randomly placed blotches on its skin that blends into the vegetation, leaves and twigs. Thus protected from detection, it can lie in wait for unfortunate prey to wander its way. Skunk is a cat sized American mammal, when threatened it squirts a fine spray of foul smelling irritant liquid from its anal gland towards its attacker.

\section{ADAPTIVE CAMOUFLAGE}

Certain animals change their color in response to different environments or situations. Certain lizards are well known for their ability to match their color to their surroundings. The chameleon is the famous example of this phenomenon. However they are not only the one who can change their color, numerous aquatic organisms also have this ability. These color changes are not always for camouflage but it also meant as messages to members of the same species. Changing colors are used to signal sexual availability, or to warn other animals of the same species. Chameleons primarily use their ability to change color to express their mood, but it is also used to blend into a new environment. Cuttle fish also assess their surrounding and take up the appropriate color. Cuttlefish also have the capacity to change the color on their entire body is less than a second, they use this ability to "flash", considered a form of communication.

\section{MOTION AND PROTECTIVE COLORATION}

Some animals are colored in such a way that they draw attention to themselves only when they are in motion. Certain birds have light colored feathers that are visible only during flight, when the birds comes to rest and their feathers are tucked under darker feathers, so that the bird is once again inconspicuous. Similarly many fishes have colorful dorsal fins that are extended while the fish is swimming then folded down when the fish is at rest. In both cases, the animal can use its coloration to perform a sort of disappearing act. It can draw a predator away from a certain area, perhaps a nest of vulnerable offspring, by catching the predator's attention and moving to another location. If the predator pursues the decoy, the bird or fish can disappear by coming to rest.

\section{MIMICRY}


In this process one species of animal resembles another species closely enough to deceive predators. In Batesian mimicry, an edible species resembles a distasteful or dangerous species. The most common example of this is butterflies, when an edible prey animal comes to resemble, even slightly with a distasteful animal, natural selection favours those individuals that even very slightly better resembles the distasteful species. This is because even a small degree of protection reduces predation and increases the chance that an individual mimic will survive and reproduce. E.g. many species of hoverfly (stingless) are colored black and yellow like bees and are in consequence avoided by birds and people.

In mullarian mimicry, two or more distasteful or dangerous animal species resemble each other. This type of mimicry is common in wasp and bees(hymenoptera), when a distasteful animal comes to resemble a more common distasteful animal natural selection favours individuals that even very slightly better resembles the target. Young bird must attack at least one insect like wasp, to learn that the black and yellow colors mean a stinging insect. If bees were differently colored, the young bird would have to attack one of them also. But bees and wasp resemble each other; the young bird need only attack one from the whole group to learn to avoid all of them. So, fewer bees are attacked if they mimic wasps; the same applies to wasp that mimics bees. The result is mutual resemblance for mutual protection. Other examples of mimicry are - owl butterfly, like many butterflies and moths that have large "eyespots" on their wings, these spots frighten off potential predator. These butterflies are mainly targeted by lizard and frog. The eyespot, which resembles the eyes of the owls, helps the butterflies evade capture.

Leaf insect shows unbelievable wonders of evolution, complete with a leaf-like network of veins; their walk is similar to a leaf being blown around in the wind, their bite marks on the edges, resembling a leaf more realistically. Other examples of mimicry of stick insect, dead leaf butterfly etc. Milk snake (nonvenomous) colored similarly to venomous and coral snakes, are afforded excellent protection due to this similarity.

\section{SIGNALLING}

Color is widely used for signalling in animals, to signal a capability or service, to other animals, whether within a species or not.

- Sexual Selection, where members of one sex choose to mate with suitably colored members of the other sex, thus driving the development of such colors.

- Warning signal, that an animal is harmful, for example it can sting, and it may be poisonous or it is bitter tasting. Warning signals may be mimicked truthfullyor untruthfully.

\section{PHYSICAL PROTECTION}

- Many animals have dark pigments such as melanin in their skin, eyes and fur to protect them-selves against sunburn.

- Some frogs, which basks in sunlight, lighten their skin color when hot (and darkens when cold), marking their skin reflect more heat and so avoid overheating.

- Some animals are colored purely incidentally because their blood contains heame pigments, needed to carry oxygen. Human albinos and people with fair skin have a similar color for the same reason. 


\section{CONCLUSION}

Protective coloration promotes preservation of life in the struggle for existence. The mechanismof protective coloration is found among many groups of invertebrates and vertebrates. All animal use their color pattern for some vital purposes, mostly to avoid becoming a prey. Some animals use as protectivearmour to ward off predator. As far as the use of color is concerned, these are the measure applications of color pattern in the animal world, and some of the animals which best employ it. Most colors and markings improved their chances of surviving. Coloration is the most visible expression of an organism genetic pattern. After several million years of evolution, most animals now achieved the color pattern most suited for their natural habitat. Protective coloration is an adaptive mechanism of animals, to reduce the risk of predation by different means. These color changes are not always for camouflage but meant as messages to members of the same species.Besides predator perception, it also helps in sexual selection, or to warn other animals and in physical protection.

\section{REFERENCES}

1. Silberglied, R., Aiello, A.and Windsor, D.M. Disruptive coloration in butterflies - lack of support in Anartia Fatima. Science. 209, 1980, 617-619.

2. Ruxton, GD. The possible fitness benefits of striped coat coloration for zebra. Mamm. Rev.2002,237-244. Doi:10.1046/j.1365-2907.2002.00108.x

3. Houston, AI., Stevens, M. and Cuthill, IC. In press. Animal camouflage: compromise or specialise in a two patch-type environment. Behav. Ecol

4. Wuster W., Do aposematism and Batesian mimicry require bright markings? A test, using European viper markings, Proc.R. Soc. B. 271, 2004, 2495-2499. doi: 10.1098/rspb.

5. Merilaita, S. and Lind, J. background-matching and disruptive coloration, and the evolution of cryptic coloration. Proc.R.Soc.B, 2005, 665-670 doi10.1098/rspb.2004.3000

6. Gilbert F. The evolution of imperfect mimicry. In: Fellowes M.D.E., Holloway G.J, Rolff Jeditors, Insect evolutionary ecology. CABI; Wallingford, CT:2005

7. Pie, MR. Signal Evolution in prey recognition systems. Behav. Proc., 68, 2005, 47-50. Doi: 10.1016/j.beproc. 2004. 11.001.

8. Vallin, A., Jakobson, S. and Wicklund, C. Prey survival by predator intimidation: an experimental study of Peacock butterfly defence against blue tits, Proc R.Soc. B., 272, 2005. 1203-1207. doi:10.1098/rspb.2004.3034.

9. Endler JA.and Meilke, PWJ., Comparing color patterns as birds see them. Biol. J.Linn., 86, 2005, 405-431. Doi:10.1111/j.1095-8312. 2005. 00540.x

10. Endler JA. Disruptive and cryptic coloration. Proc. R.Soc.B, 273, 2006, 2425-2426. doi:10.1098/rspb.2006.3650C

11. Martin, S., predator perception and the inter relation between different forms of protecting coloration. Proc. Biol. Sci., 274, 2007, 1457-1467.

12. Animal protective coloration.http://boscage.info/index.php.

13. Animal coloration.http.//en.wikipedia.org

14. Protective coloration and form.http.//encyclopaedia 2.thefreedictionary.com 